\title{
Desafíos para el mantenimiento de una esfera pública democrática en la sociedad digital
}

Challenges to the existence of a democratic public sphere in the digital society

\author{
JuAn María Martínez OTERo' \\ Universidad de Valencia, España
}

\begin{abstract}
RESUMEN El presente trabajo se propone analizar cómo el creciente protagonismo de las redes sociales en el debate público puede implicar -de forma contraintiutiva- serios riesgos para la construcción y el mantenimiento de una esfera pública democrática. Para ello, en primer lugar, se identificarán las que hasta ahora han sido consideradas como características esenciales de una esfera pública democrática, exponiendo cómo dichas características han sido reconocidas y protegidas en los ordenamientos jurídicos -tomando como referencia el ordenamiento jurídico español. Enumeradas estas características, el trabajo analiza cómo la dinámica de las redes sociales puede poner en jaque cada una de ellas. Presentados los peligros que un mal uso de las redes comporta para la esfera pública, el estudio concluye ofreciendo un catálogo de medidas que poderes públicos, industria y usuarios de Internet pueden adoptar con el fin de sortear los riesgos apuntados y contribuir a la preservación de un espacio público libre y robusto, presupuesto irrenunciable de toda democracia.
\end{abstract}

PALABRAS CLAVE Esfera pública; Redes sociales; Democracia; Pluralismo; Transparencia.

1. Juan Martínez Otero es profesor Ayudante Doctor en el Departamento de Derecho Administrativo y Procesal de la Universidad de Valencia (España). Entre sus principales áreas de estudio se encuentran la protección de los menores en el entorno audiovisual y los desafíos que plantea al Derecho el avance de las tecnologías de la comunicación. Ha realizado estancias de investigación en las Universidades de Oxford, Cambridge y King's College London. Mail: juan.maria.martinez@uv.es. 
ABSTRACT The present paper discusses how the growing prominence of social networks in public debate can imply serious risks for the public sphere, and therefore pose a real threat to democracy itself. First, the paper identifies the basic characteristics of a typical democratic public sphere (pluralism, diversity, transparency, communality, veracity), presenting how these characteristics are guaranteed by Spanish Media Law. Second, the paper discusses how the dynamics of social networks can jeopardize each of those characteristics. The analysis will be based on a review of the most recent bibliography on the subject. Having presented the dangers that misuse of social networks entails for the public sphere, the study concludes by offering a catalogue of measures that public authorities, industry and Internet users can adopt to overcome the risks identified, and to foster a free, robust public space, which is a conditio sine quae non for the existence of a democracy.

KEYWORDS Public sphere; Social networks; Democracy; Pluralism; Transparency.

\section{Introducción: las redes sociales, ágora del siglo XXI}

La pervivencia de una democracia depende en gran medida de su capacidad de establecer y mantener una esfera pública sana, entendida ésta como el entorno común de debate e intercambio de ideas acerca de las cuestiones de interés general ${ }^{2}$. La esfera pública se configura pues como el espacio donde las diferentes posiciones e ideas sobre la res publica entran en diálogo, contribuyendo a formar la opinión pública. La opinión pública, a su vez, determina la conformación de la voluntad general, que se materializa de forma mediata en la aprobación de normas generales, así como en un control político difuso sobre el modo en que es ejercido en poder ${ }^{3}$.

La evolución histórica de la esfera pública y su íntima conexión con la democracia excede con mucho el propósito de estas páginas. Valga señalar como antecedentes remotos de nuestra esfera pública mediática el ágora griega o el foro de la Roma republicana ${ }^{4}$ y, como antecedentes más próximos, los salones, clubes y casinos que

2. CANO-ORÓN y LLORCA-ABAD (2018) p. 108. No se nos escapa que el concepto de "esfera pública" es sumamente complejo y poliédrico. En el presente estudio nos referiremos a ella en el estricto sentido que acabamos de definir. Para una discusión en profundidad sobre el alcance del concepto "esfera pública" resulta de interés: PÉREZ-DÍAZ (1997) pp. 61 y ss.

3. ARIAS MALDONADO (2016) p. 26; RODRÍGUEZ URIBES (1999) pp. 200 y ss. y 333 y ss.

4. Estos antecedentes remotos han de ser tomados con cautela. En efecto, como recuerda SARTORI (1988) p. 352, en la Grecia clásica "la distinción entre esfera pública y esfera privada era desconocida, y hubiera sido ininteligible para el polites". El abismo conceptual que separa la concepción clásica y la contemporánea sobre la participación ciudadana en los asuntos públicos fue explicado certeramente por CONSTANT (1989) pp. 257-285 en su famosa conferencia De la libertad de los antiguos comparada con la libertad de los modernos, pronunciada en 1819. 
aparecen a lo largo del siglo XVIII, así como las primeras publicaciones periódicas de carácter literario, cultural y satírico, que comienzan a generalizarse en Europa en el mismo siglo ${ }^{5}$. A lo largo del siglo XIX el debate sobre las cuestiones de interés general va canalizándose paulatinamente a través de la prensa escrita, que actúa como catalizador de la opinión pública ${ }^{6}$. En la primera mitad del siglo XX la esfera pública se extiende a las ondas de la radio, primer medio de comunicación "de masas"; al tiempo que en la segunda mitad de dicho siglo la televisión adquiere una preeminencia indiscutible como principal arena pública ${ }^{7}$. Prensa, televisión y radio han configurado en muy buena medida la esfera pública en las últimas décadas, hasta el cambio de siglo. Este innegable protagonismo de los medios de comunicación en la conversación pública - que ha llevado a algunos autores a hablar de la democracia mediática o de la democracia de audiencias ${ }^{8}$ - permite una cierta equiparación entre el entorno comunicativo delimitado por los medios de comunicación, y la esfera pública.

El advenimiento de Internet y la explosión del uso de las redes sociales han supuesto una verdadera convulsión del espacio público tradicional ${ }^{9}$. A los tres medios de comunicación clásicos, sobre los que se ha articulado el debate público en las últimas décadas - prensa, radio, televisión-, ha venido a sumarse un nuevo canal de comunicación que está suponiendo una reconfiguración de la esfera pública que -sin sombra de hipérbole- cabe calificar de dramática ${ }^{10}$.

En las páginas que siguen utilizamos la expresión "red social" en el sentido que a esta expresión confiere el Diccionario de la Real Academia Española, es decir, para hacer referencia a una "plataforma digital de comunicación global que pone en contacto a gran número de usuarios" ${ }^{11}$. Dicho en términos algo más técnicos, a los efectos del presente estudio una red social es un servicio -habitualmente, una plataforma web o una aplicación- que permite a sus usuarios construir un perfil público o semipúblico dentro de un sistema restringido, crear una comunidad en línea con otros

\footnotetext{
5. HABERMAS (2002) pp. 43-68.

6. MUÑOZ-ALONSO (1990) p. 41.

7. MONZÓN (2008) p. 208.

8. VALLESPÍN (2003); MANIN (1998).

9. VALLESPÍN (2015) p. 46.
}

10. DEL REY MORATÓ (2007) describió acertadamente esta revolución anunciando el giro de la teledemocracia a la ciberdemocracia.

11. Conviene aclarar desde el arranque que la idea de "red social" es anterior e independiente a las herramientas tecnológicas a las que nos referimos en el presente trabajo. Dichas herramientas digitales permiten extender, robustecer y dinamizar las redes sociales existentes en el mundo offline, al tiempo que establecer nuevas redes surgidas directamente en el entorno digital. Para una exposición omnicomprensiva del concepto de red social, resulta de interés KADUSHIN (2013). Como hemos señalado, en este estudio utilizaremos la expresión "red social" en su acepción coloquial, que se refiere a determinados servicios ofrecidos a través de Internet. 
usuarios con quienes se comparten puntos en común, y explorar su lista de contactos y la de los otros usuarios dentro del mismo sistema ${ }^{12}$. A través de las redes sociales se puede compartir información mediante la utilización de servicios de mensajería personal, microblogging, publicación de mensajes y fotografías, formación de grupos de interés, etc ${ }^{13}$. Al momento de escribir las presentes líneas, entre las redes sociales más extendidas en el mundo se encuentran Facebook, Twitter, Instagram, YouTube, Whatsapp, Tik Tok, LinkedIn y Wechat.

Desde su aparición y generalización, la incidencia de las redes sociales en la conformación del espacio público es creciente, hasta el punto de que están sustituyendo o asimilando otras formas más tradicionales de acceso a la información y participación en el debate público. El carácter omnipresente las redes sociales -accesibles de forma inmediata desde cualquier dispositivo móvil-, su insólita personalización y su naturaleza eminentemente bidireccional e interactiva han convertido estos entornos en el espacio público de referencia ${ }^{14}$, el nuevo ágora del siglo XXI. No parece atrevido sostener que estas nuevas herramientas de comunicación resultan idóneas para alterar la fisonomía de nuestros sistemas democráticos, abriendo la puerta a formas de democracia más deliberativas, en la línea de lo preconizado por Mansbridge (1992) o Barber (2004), y posibilitando la contestación y el control permanente de las decisiones de los gobernantes mediante el discurso en las redes sociales (aspiración típica del republicanismo que encontramos, por ejemplo, en Pettit ${ }^{15}$ ).

Dejando a un lado dichas posibilidades, ciertamente prometedoras, el propósito de estas páginas se circunscribe a analizar cómo el creciente protagonismo de las redes sociales en el debate público puede implicar una serie de riesgos para la esfera pública, erigiéndose por ende en una verdadera amenaza para la propia democracia.

Para ello, tras identificar las que hasta ahora han sido consideradas como características básicas de una esfera pública típicamente democrática - pluralismo, diversidad, transparencia, comunalidad, veracidad-, y exponer sucintamente la forma en que el Derecho público ha procurado salvaguardarlas, nos detendremos en estudiar empíricamente cómo la dinámica de las redes sociales puede poner en jaque cada una de esas características ${ }^{16}$.

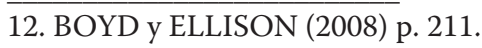

13. ROS-MARTIN (2009) p. 554.

14. CANO-ORÓN y LLORCA-ABAD (2018) p. 106.

15. PETTIT (2001) pp. 160-167.

16. El ordenamiento jurídico tomado como referencia será el español, si bien la inmensa mayoría de ordenamientos jurídicos -al menos los americanos y los europeos- cuentan con preceptos análogos. 
A título de advertencia previa, es preciso subrayar que estas características básicas de la esfera pública no dejan de ser objetivos ideales, cuya consecución perfecta resulta inalcanzable. Aunque en el presente estudio analizaremos los peligros que estas notas definitorias afrontan en el ámbito comunicativo configurado por las redes sociales de Internet, no debe olvidarse que en contextos comunicativos previos a Internet estas características también sufrieron desafíos y amenazas, nunca totalmente resueltos. En efecto, cada época cuenta con un contexto mediático y comunicativo diferente, donde las ventajas y los obstáculos para la existencia de una esfera pública democrática y de una opinión pública libre son distintos.

Constatados los peligros que un mal uso de las redes comporta para la esfera pública, el estudio se cierra ofreciendo un catálogo -inevitablemente tentativo y provisional- de medidas que poderes públicos, industria y usuarios de Internet pueden adoptar con el fin de sortear los riesgos apuntados y contribuir a la preservación de un espacio público libre y robusto, presupuesto irrenunciable de toda democracia.

\section{Características esenciales para la existencia de una esfera pública democrática}

Como se ha tenido ocasión de apuntar, a lo largo del siglo XX la esfera pública se articula progresivamente en torno a la prensa escrita y a los dos grandes medios de comunicación de masas inventados en dicha centuria: la radio y la televisión.

No sin ciertos titubeos, los Estados van delineando el marco normativo aplicable a estos medios, marco que se orienta principalmente a salvaguardar determinados intereses públicos en el nuevo espacio mediático - protección de los menores, orden público, pluralismo comunicativo-, así como a proteger ciertos derechos individuales particularmente vulnerables en el entorno mediático, como el honor, la intimidad o la propia imagen.

Las sucesivas regulaciones de los medios de comunicación -en conjunción con el acervo constitucional en materia de derechos comunicativos y una acendrada jurisprudencia en relación con los mismos- van acrisolando un conjunto de intereses públicos imprescindibles para el mantenimiento de un espacio mediático sano, sustrato necesario para la existencia de una opinión pública libre.

Veamos a continuación -a la luz del ordenamiento jurídico español- cuáles son dichos intereses públicos que se configuran como condiciones para la existencia de una esfera pública democrática. Una vez identificados los mismos, estaremos en condiciones de cuestionarnos hasta qué punto el creciente protagonismo de las redes sociales en la esfera pública puede implicar su erosión o, lisa y llanamente, su liquidación. 


\subsection{El pluralismo}

Un primer principio fundamental en el entorno comunicativo es el pluralismo, que implica la existencia de una pluralidad de medios y de voces que reflejen en el ámbito comunicativo, el pluralismo existente en la sociedad. El pluralismo político es uno de los valores superiores del ordenamiento jurídico, como consagra el artículo $1.1^{\circ}$ de la Constitución española. En buena lógica, un entorno mediático democrático necesariamente deberá ser plural ${ }^{17}$. Así lo ha recordado frecuentemente el Tribunal Constitucional español, señalado que la defensa de los derechos comunicativos implica "la garantía de una institución política fundamental, que es la opinión pública libre, indisolublemente ligada con el pluralismo político que es un valor fundamental y un requisito del funcionamiento del Estado democrático" ${ }^{18}$.

\subsection{La diversidad}

Íntimamente unida al pluralismo, se ha reconocido asimismo la trascendencia de la diversidad, consistente en la posibilidad de acceder a contenidos variados en cuanto a su temática, idioma, formato y proveniencia ${ }^{19}$. Este principio, reconocido como un derecho de la audiencia en el artículo 5 de la Ley 7/2010, de 31 de marzo, General de la Comunicación Audiovisual (en adelante, LGCA), está profundamente relacionado con la defensa de la cultura y la identidad propia, en un entorno globalizado donde la colonización cultural por parte de otras industrias extranjeras es un riesgo innega$b e^{20}$. La defensa de la diversidad parte del convencimiento de que una esfera pública democrática es una esfera pública heterogénea, donde coexisten mensajes de diversa

17. BOCANEGRA (2012) p. 5. La Ley 7/2010, de 31 de marzo, General de la Comunicación Audiovisual, reconoce el derecho a recibir una comunicación audiovisual plural en su artículo 4. Junto con ello, sus artículos 36 y 37 establecen una serie de garantías para la preservación del pluralismo en el mercado audiovisual. Por su parte, la Ley 17/2006, de 5 de junio, de la radio y la televisión de titularidad estatal, incluye en sus artículos 2 y 3 el pluralismo como uno de los conceptos básicos del servicio público radiotelevisivo. Para un análisis monográfico sobre el pluralismo comunicativo y su alcance en la Constitución española, véase: RALLO LOMBARTE (2000).

18. STC 12/1982, de 31 de marzo, F.J. $3^{\circ}$.

19. A fin de garantizar la diversidad, el artículo 5 LGCA impone a los prestadores de servicios de comunicación audiovisual ciertas obligaciones de cuota de pantalla y de financiación anticipada de obra europea.

20. DE LA SIERRA y GONZÁLEZ (2012) p. 18. Los artículos 2 y 3 de la Ley 17/2006, de 5 de junio, de la radio y la televisión de titularidad estatal, contienen también previsiones tendentes a garantizar la diversidad en la programación de RTVE. 
índole, hay lugar para contenidos minoritarios, y se evita la estandarización monocroma tantas veces resultante del juego ciego de las fuerzas del mercado.

\subsection{La transparencia}

En tercer lugar, el principio de transparencia aplicado a los medios garantiza el derecho de la audiencia a conocer quién es el titular de cada medio y el responsable editorial de cada contenido ${ }^{21}$. Esta información permite a los ciudadanos comprender mejor los posibles sesgos en los mensajes que reciben, y decidir responsablemente el crédito que quieren conferir a las informaciones y opiniones contenidas en cada medio de comunicación. En relación con el principio de transparencia, es preciso referirse asimismo a la honestidad o autenticidad publicitaria, que garantiza el derecho de la audiencia a identificar las comunicaciones comerciales como tales, derecho que tiene como envés la prohibición de toda forma de publicidad encubierta o disfrazada ${ }^{22}$. En la esfera pública, la transparencia se demuestra como uno de los mejores antídotos contra la manipulación, que siempre se sirve de ocultamientos y añagazas para condicionar de forma partisana el debate público.

\subsection{La veracidad de las informaciones}

Un cuarto principio o requisito para el mantenimiento de un espacio público democrático es la veracidad de las informaciones que son compartidas y discutidas en el mismo. En este sentido, es preciso recordar que el artículo $20.1^{\circ}$.d de la Constitución reconoce el derecho a la información veraz, de modo que extiende su protección tan solo a las informaciones que hayan sido debidamente contrastadas, obtenidas con rigor y profesionalidad, al tiempo que deja sin protección constitucional aquellas otras informaciones falsas o inveraces ${ }^{23}$. El establecimiento de la veracidad como límite al

21. El derecho a una comunicación audiovisual transparente se reconoce en el artículo 6 LGCA. Respecto de los medios impresos, la transparencia se garantizó históricamente mediante la obligación de "pie de imprenta", recogida actualmente en el artículo 11 de la preconstitucional Ley 14/1966, de 18 de marzo, de Prensa e Imprenta. Por último, y en relación con Internet, el artículo 10 la Ley 34/2002, de 11 de julio, de Servicios de la Sociedad de la Información exige a los prestadores de servicios en Internet ciertas obligaciones de información general.

22. La principal prohibición de publicidad encubierta en nuestro ordenamiento se encuentra en el artículo 26 de la Ley 3/1991, de 10 de enero, de Competencia Desleal. Con carácter sectorial, contienen exigencias para garantizar la autenticidad publicitaria el artículo 13 LGCA, así como el Real Decreto 2198/1976, de 23 de julio, por el que se dictan normas para la aplicación del principio de autenticidad en materia publicitaria, todavía vigente a pesar de su innegable anacronismo.

23. Sobre el particular, y entre muchas, véase: SSTC 76/2002, de 8 de abril; 136/2004, de 13 de septiembre; y 29/2009, de 26 de enero. 
derecho a la información no tiene como fin exclusivo proteger al destinatario individual de la información frente a mensajes trapaceros o falaces, sino también salvaguardar el interés colectivo en que la información disponible sea veraz ${ }^{24}$. Y ello porque un entorno comunicativo dominado por los bulos, los rumores y las mentiras - por información no contrastada-, es el mejor caldo de cultivo para la desorientación y la destrucción del debate público ${ }^{25}$.

\subsection{La existencia de un espacio común}

A lo anteriormente expuesto cabría añadir una quinta conditio sine quae non para el mantenimiento de un espacio público democrático: su existencia como entorno común, como espacio compartido. Hasta la fecha este principio de "comunalidad" no ha sido positivizado explícitamente en ningún cuerpo normativo, probablemente por el hecho de que los medios de comunicación tradicionales se caracterizaban, de suyo, por esa naturaleza compartida, abierta o universal, al dirigir sus mensajes una generalidad ciertamente amplia de receptores. En cualquier caso, sí cabe espigar en la normativa audiovisual previsiones tendentes a garantizar este carácter "comunal" o "compartido" de los medios. Así, por ejemplo, la concepción de los servicios audiovisuales televisivos como servicios públicos o de interés general, cuya recepción debe garantizarse a toda la población (art. 2.3 Ley 17/2006); las obligaciones de accesibilidad de los contenidos para las personas con discapacidad (art. 7 LGCA); la obligación de emitir en abierto los acontecimientos de interés general (art. 20 LGCA); o las obligaciones de must carry, con el fin de hacer llegar la señal de los canales a un mayor número de receptores (art. 11 LGCA). Todas estas medidas tienen como fin garantizar la existencia de un entorno mediático compartido y accesible para todos, que se configure como una esfera pública de discusión democrática.

24. Esta doble dimensión -objetiva y subjetiva- de los derechos constitucionales ha sido reconocida desde un momento temprano por la jurisprudencia constitucional. En este sentido, véase por todas la STC 25/1981, de 14 de julio, F.J. 5º. SOLOZÁBAL ECHEVARRÍA (2018) p. 1 subraya con acierto que la libertad de expresión constituye el ejemplo paradigmático de esta doble dimensión de los derechos fundamentales, que protegen tanto intereses individuales como colectivos.

25. El principio de veracidad de la información también se reconoce legalmente en el artículo 3.b de la Ley $17 / 2006$, y en el $4.5^{\circ}$ LGCA. 


\section{Riesgos para el mantenimiento de una esfera pública democrática derivados de la dinámica propia de las redes sociales}

Una vez enumeradas las cinco características que una esfera pública debe revestir para poder ser considerada como democrática, a continuación se analiza cómo el entorno comunicativo configurado por las redes sociales -contra lo que pudiera parecer- puede minar cada una de esas cinco propiedades, convirtiendo la esfera pública en un entorno opaco, atomizado, oligopolístico y saturado de falsedades.

Para sortear la tentación del determinismo tecnológico -ciertamente atractivo, como muchas visiones apocalípticas y distópicas- conviene advertir al lector que los riesgos que se van a presentar están siendo objeto de un encendido debate a nivel internacional: en muchos casos, su potencialidad fáctica no ha sido hasta el momento demostrada; en otros, su incidencia está siendo progresivamente desmentida o relativizada ${ }^{26}$.

También es oportuno no perder de vista que la ambivalencia del progreso tecnológico puede convertir las redes sociales de Internet en valiosas aliadas para el debate público, si se adoptan al respecto las decisiones -normativas, tecnológicas, empresariales y de consumo- adecuadas ${ }^{27}$.

Si a continuación se describen en toda su crudeza los potenciales riesgos, dibujando el peor escenario de los posibles, no es porque sostengamos que dicho escenario ya está aquí o advendrá de manera inevitable, ni tampoco para justificar una intervención pública rápida y decidida en este ámbito, que podría resultar desastrosa para el respeto a los derechos comunicativos. Nuestra intención al describir un panorama tan poco halagüeño para el futuro de la esfera pública en la era de las redes sociales es invitar a la reflexión y propiciar un debate sereno y responsable al respecto, tan distante del tecnoentusiasmo ingenuo como de la tecnofobia determinista y ludita.

26. Tras un estudio sobre los efectos de los filtros burbuja, las cámaras de resonancia y las fake news, conducido en siete países y con 14.000 participantes, DUTTON et al. (2017) alertan sobre el riesgo de reaccionar de forma desproporcionada para atajar unos peligros más imaginarios que reales, sobredimensionados por narrativas deterministas y poco matizadas. En similar sentido, PETIT (2018) p. 8 se pregunta si estos discursos distópicos no serán alarmistas, interesados o ideológicos con la intención de justificar eventuales políticas públicas de carácter intervencionista.

27. RUBIO NÚÑEZ (2018) p. 222 enumera una serie de oportunidades positivas, entre las que destaca: "la democratización de la información, con el acceso universal a la misma y la oportunidad de cualquiera para convertirse en emisor, dotando de visibilidad a puntos de vista alternativos que no suelen tener espacio en los medios de comunicación tradicionales; la capacidad de autoorganización de manera rápida y con un coste reducido, con la consiguiente desintermediación de la política; las posibilidades de movilización de ciudadanos previamente inactivos". 
La clarividencia y determinación que se requieren para embridar unas herramientas tan poderosas y ponerlas al servicio del interés público no nos advendrán por arte de magia - deus ex machina-, sino que serán el fruto maduro de una reflexión profunda y matizada que, junto a las maravillosas oportunidades que las redes sociales nos brindan, tenga también muy presentes en toda su gravedad sus ya evidentes amenazas.

\subsection{El peligro de los oligopolios: el network effect como amenaza para el pluralis- mo y la diversidad}

Internet y las redes sociales dan la posibilidad de participar en el debate público a cualquier persona, siempre y cuando cuente con las debidas habilidades digitales y una conexión a la Red. De este modo, las redes sociales han permitido la explosión del número de canales de información, lo que prima facie implica un innegable incremento del pluralismo y la diversidad. Sea de ello lo que fuere, conviene no perder de vista que en la mayoría de los modelos de negocio en Internet -buscadores, redes sociales, tiendas online- se da una acusada tendencia al monopolio, que puede resultar nociva para el pluralismo y la diversidad.

La propensión de los usuarios de Internet a aglutinarse en unas pocas redes sociales -como Facebook, Instagram o Youtube- ha sido explicada mediante la teoría del network effect, que afirma que el valor de una red depende del número de personas que la utilizan. En virtud del network effect, una vez que una red se convierte en mayoritaria resulta muy difícil que sea desplazada por otra red incipiente que pretenda competir por el mismo mercado ${ }^{28}$. La teoría del network effect da razón de por qué, a pesar de que Internet permite la existencia de un número casi infinito de redes sociales, los usuarios se congregan en torno a muy pocas plataformas líderes en su sector a nivel mundial -v.g. LinkedIn, Facebook o Instagram-, que monopolizan las interacciones en redes a nivel mundial. Winner-takes-all, el ganador se lo lleva todo, es otra expresión a la que se ha recurrido para describir esta aparente ley en virtud de la cual, en Internet, una vez que una plataforma se convierte en líder, casi automáticamente deviene en monopolística ${ }^{29}$.

Más allá de los peligros económicos ínsitos a toda estructura de mercado cercana al monopolio, la concentración empresarial existente en el ámbito de las redes sociales plantea importantes cuestiones vinculadas con la existencia de una esfera pública

28. Sobre el particular, resulta de interés: IBRUS y ROHN (2016) pp. 4 y ss.

29. KEEN (2015) pp. 43 y ss. 
sana y con el libre ejercicio de los derechos comunicativos ${ }^{30}$. El hecho de que unas pocas entidades -todas ellas privadas, de carácter empresarial y radicadas en Estados Unidos- controlen el espacio en el que el debate público se produce, canalizando la práctica totalidad de los mensajes, conlleva innegables riesgos para el pluralismo y la diversidad ${ }^{31}$.

En primer lugar, los servicios de redes sociales presentan y ordenan sus contenidos conforme a su propio criterio, lo que puede implicar sesgos ideológicos, culturales o políticos tendentes a dirigir la opinión o el debate público en un determinado sentido $^{32}$. Si tenemos en cuenta que en torno al $65 \%$ del acceso a noticias en Internet no es directo, sino que se produce mediante intermediarios -redes sociales, buscadores, agregadores de noticias-, resulta difícil exagerar la importancia de los riesgos que implica la existencia de monopolios en este sector ${ }^{33}$.

En segundo lugar, la propia arquitectura de estas redes determina qué contenido se produce y cuál es su visibilidad, primando por ejemplo los mensajes cortos a los largos; los visuales a los escritos; los producidos en un idioma muy extendido respecto de aquellos en idiomas minoritarios; o los controvertidos respecto de los moderados ${ }^{34}$ Así, mientras un tipo de mensaje será idóneo para tener visibilidad en

30. De forma quizá un poco categórica, ÁLVARO (2018) p. 75 ha señalado: "los pioneros del ciberespacio Pierre Levy (1994) y Manuel Castells (1996) teorizaron la web como nueva esfera pública, el lugar para la comunicación masiva de un nuevo empoderamiento colectivo, gracias a la accesibilidad colectiva de los medios de publicación y edición. Hoy en día esta esfera pública agoniza bajo el monopolio de las grandes compañías de medios y de la administración algorítmica que gobierna la comunicación en red".

31. HELBERGER (2018) pp. 155-158. La misma autora apunta de forma lúcida lo paradójico que resulta que las redes sociales, que propician la multiplicación exponencial de canales y emisores, puedan constituir al mismo tiempo una verdadera amenaza para el pluralismo y la diversidad.

32. Muy tempranamente, INTRONA y NISSENBAUM (2000) alertaron sobre los riesgos que entrañaba para el pluralismo el hecho de que los buscadores de Internet más extendidos excluyeran de sus resultados de búsqueda determinadas páginas web, en función de criterios opacos o exclusivamente comerciales. En sentido similar, resulta interesante el informe publicado por Ofcom en 2012, sobre el pluralismo en los medios de comunicación: Measuring Media Plurality, Ofcom (2012) pp. 25 y ss.

33. KALOGEROPOULOS y NEWMAN (2018) p. 6.

34. IBRUS y ROHN (2016) p. 5 recuerdan que las principales plataformas de intercambio de contenidos no están diseñadas para servir a culturas nacionales o locales, teniendo en cuenta sus peculiaridades. Por consiguiente, los contenidos más populares o mainstream gozan de una visibilidad notablemente superior a otros contenidos de carácter más local o minoritario; lo que paulatinamente hace al primer tipo de contenido omnipresente, y al segundo invisible. 
la plataforma, otro será ineluctablemente arrumbado a los arrabales del servicio por no ajustarse a los estándares preferidos por el algoritmo. Esta circunstancia propicia que los emisores se adapten a las pautas de la plataforma y elaboren sus contenidos conforme a las preferencias de cada red social, lo que innegablemente reduce la diversidad $^{35}$.

En tercer lugar, e íntimamente asociado a lo anterior, cabe subrayar la influencia indirecta que las redes sociales están ejerciendo sobre los medios de comunicación tradicionales, cuya conexión con la audiencia depende en buena parte de las decisiones y políticas de las redes sociales. El desplazamiento del acceso a la información de la fuente primaria - el medio de comunicación- a la red social desdibuja la identidad del medio, le resta visibilidad y puede privarle de ingresos económicos ${ }^{36}$. Todo ello está determinando un progresivo debilitamiento de los medios de comunicación tradicionales, con la consiguiente merma para la independencia periodística, la calidad de la información y el pluralismo ${ }^{37}$.

A este conjunto de factores que pueden poner en peligro el pluralismo y la diversidad de la esfera pública, es necesario añadir el control de los mensajes que las propias redes están comenzando a efectuar, ya sea por política de empresa o por un progresivo requerimiento legal. Esta fiscalización -amparada siempre en intereses difícilmente criticables como la protección de los niños, el derecho al olvido, o la lucha contra la discriminación y el discurso del odio-, abre no obstante la puerta a una censura de carácter privado y difuso, que puede empobrecer el debate público de forma casi invisible y cercenar injustificadamente manifestaciones legítimas de los derechos comunicativos ${ }^{38}$.

35. PARRA Y OLIVEIRA (2018) p. 60.

36. COTINO HUESO (2013) pp. 55-56; KALOGEROPOULOS y NEWMAN (2018) pp. 10 y ss.

37. Así lo constata la Declaración Conjunta sobre Libertad de Expresión y Noticias Falsas, Desinformación y Propaganda de la ONU, la OSCE, la OEA y la CADHP, de 3 de marzo de 2017, p. 2.

38. NAVARRO (2018); BOIX PALOP (2016) pp. 72-74 señala con intuición que los responsables de las redes, cuando tengan dudas razonables sobre la legalidad de un contenido, en la disyuntiva de si mantenerlo o retirarlo, preferirán habitualmente pasarse "por carta de más” y eliminar el contenido, para evitar enfrentarse a hipotéticas responsabilidades jurídicas derivadas de no haberlo hecho, con la consiguiente merma de los derechos comunicativos. 
No han pasado ni quince años desde la creación de las primeras redes sociales de Internet, y ya comienza a estar claro para muchos que su impacto en relación con el pluralismo comunicativo y la diversidad puede ser contraintuitivo.

\subsection{El peligro de la opacidad}

Frente al paradigma del espacio comunicativo transparente, en el que el ciudadano conoce la identidad de los emisores de los mensajes y la titularidad de los medios de comunicación, el entorno de las redes sociales de Internet puede ser acusadamente opaco.

\subsubsection{Opacidad de los algoritmos}

Una primera causa de opacidad radica en el propio funcionamiento de los algoritmos empleados por las redes sociales y los buscadores, que seleccionan automáticamente el contenido que se ofrece a los usuarios de Internet. La falta de transparencia de los algoritmos despliega sus efectos a un doble nivel. En primer lugar, la invisibilidad de los algoritmos puede hacerlos pasar inadvertidos para muchos usuarios de Internet, que no son conscientes de que el contenido al que acceden es presentado siguiendo unos criterios predeterminados que nunca son neutrales ${ }^{39}$. Así, el mero hecho de decidir qué contenido se ofrece al usuario y cuál no, posibilita a los responsables de las redes el ejercicio de un cierto control ideológico o mental sobre sus usuarios, control que a menudo pasa desapercibido ${ }^{40}$. En segundo lugar, y aun en el caso de tener conciencia del sesgo que todo algoritmo necesariamente implica, lo habitual es que los usuarios no tengan acceso a los criterios e intereses que determinan el funcionamiento del algoritmo, ya sean económicos o de otra índole. Y ello porque al día de hoy los algoritmos constituyen secretos industriales de primer orden, que los prestadores de servicios custodian celosamente. Este desconocimiento dificulta a los usuarios la asunción de estrategias defensivas idóneas para mitigar el efecto de dichos sesgos y evitar una posible manipulación.

Ante esto, podría señalarse que resulta comprensible que las empresas tecnológicas pretendan mantener en secreto los algoritmos en los que se basan los servicios que prestan. Ahora bien, atendiendo al hecho de que los citados algoritmos influyen decisivamente en la adopción de decisiones que afectan a un creciente número de intereses generales - desde la determinación de la agenda política hasta la estabilidad del mercado bursátil-, quizá pueda esgrimirse un interés público para justificar

39. ÁLVARO (2018) p. 75.

40. CANO-ORÓN y LLORCA-ABAD (2018) p. 110. 
su fiscalización por los usuarios o por el poder público ${ }^{41}$. Una defensa a ultranza del carácter reservado de los algoritmos nos llevaría a lo que Pasquale (2015) ha denominado the black box society, una sociedad regida en muchos ámbitos por una serie de operaciones y decisiones algorítmicas ajenas a control alguno, con los consiguientes riesgos de abuso de poder.

\subsubsection{Propaganda política encubierta}

Una segunda preocupación en relación con la opacidad de las redes radica en la evidente posibilidad de que los datos obrantes en las mismas sean utilizados para fines distintos de los acordados entre la plataforma y sus usuarios. Cuando la finalidad de este uso espurio de los datos - por la propia plataforma, por terceros interesados que pagan por los datos, o por hackers- desborda lo meramente económico y entre en el campo de lo ideológico o lo político, los peligros de la opacidad revisten una trascendencia particularmente grave, en la medida en que afectan a esferas de la personalidad más profundas y a aspectos de la organización social más nucleares ${ }^{42}$.

Habida cuenta del enorme potencial de los datos en poder de las redes para influir la opinión de las personas y en el debate público, resulta imperdonablemente ingenuo pensar que quien tiene acceso a esa información va a circunscribir su uso a finalidades estrictamente económicas o publicitarias ${ }^{43}$. Así, las actividades de la empresa Cambridge Analytica en el contexto de las elecciones estadounidenses y el referéndum del Brexit en 2016 pudieron constituir un escándalo, mas en ningún caso una sorpresa ${ }^{44}$. La herramienta estaba ahí, y tarde o temprano iba a ser utilizada ${ }^{45}$.

41. PAUNER (2018) p. 314. Sobre el impacto de las redes sociales para determinar la agenda setting, se ha ocupado entre nosotros LÓPEZ GARCÍA (2016).

42. CASTELLANOS (2019) p. 11 señala acertadamente que los responsables de ciertas redes sociales "conocen tan en profundidad al objeto en cuestión, al elector, que pueden predecir su respuesta electoral y, por tanto, destacarlo como target de campaña o introducirlo en determinados sectores a los que se pretende captar".

43. Un inventario completo de los posibles agentes que pueden estar interesados o desarrollar esta manipulación de la opinión pública a través de las redes es ofrecido en: BRADSHAW y HOWARD (2017) pp. 14 y ss.

44. Los perfiles creados por Cambridge Analytica permitieron dirigir propaganda política encubierta a 87 millones de cuentas de Facebook, con el fin de influir en los resultados de las elecciones presidenciales de Estados Unidos y el referéndum del Brexit en 2016. Cfr. PETIT (2018) p. 7.

45. SUÁREZ-GONZALO (2018) p. 33. 
Este uso encubierto de los datos personales para fines políticos -para distribuir lo que Wolley y Howard (2017) han denominado "propaganda computacional"- plantea numerosísimos interrogantes en ámbitos muy variados, que van desde el derecho la intimidad o al carácter secreto del voto ${ }^{46}$, pasando por la protección de datos de los usuarios y la prohibición de la publicidad encubierta, hasta la legitimidad de la publicidad política o electoral en los medios audiovisuales o fuera de la campaña electo$\mathrm{ral}^{47}$. Por todo ello, no parece exagerado afirmar que el uso de las redes sociales para influir subrepticiamente en las opiniones políticas de los usuarios y alterar los resultados de los procesos electorales es uno de los retos más espinosos que los sistemas democráticos contemporáneos deben afrontar.

\subsubsection{Avatares, trolls y bots}

Un tercer envite a la transparencia en la esfera pública digital es el protagonismo que desempeñan en Internet los perfiles anónimos. El anonimato en la Red, como es sabido, puede constituir una garantía para la libertad de expresión. En cualquier caso, el precio de dicha libertad es la falta de transparencia en el entorno digital, donde a menudo es imposible saber quién está detrás de un determinado perfil o es responsable de un contenido en Internet.

Este anonimato facilita la actuación de trolls, personas que operan en las redes sociales y foros de Internet con fines fundamentalmente partidistas y destructivos, distorsionando intencionadamente el debate público y obstruyendo la conversación ajena.

Al ruido generado por los trolls hay que añadir la extendida presencia de bots, programas informáticos o algoritmos que replican comportamientos humanos en la Red. Aunque resulta complicado ofrecer una medición exacta acerca de la presencia y actividad de los bots en Internet, los estudios más recientes estiman que más del 10\% de los contenidos de las redes sociales y un $62 \%$ de todo el tráfico de Internet es generado por este tipo de instrumentos ${ }^{48}$. Los bots -objetos tecnológicos que se convierten en agentes $^{49}$ - son capaces de producir contenido, interactuar con los usuarios y generar artificialmente estados de opinión o falsas comunidades online, con la intención de

46. CASTELLANOS (2019) pp. 27-28.

47. SUÁREZ-GONZALO (2018) p. 32. Y también, PETIT (2018) p. 6.

48. WOLLEY Y HOWARD (2017) p. 13.

49. ÁLVARO (2018) p. 75. 
modular el debate e influir en la opinión pública ${ }^{50}$. Como explica Petit, en las redes sociales los bots pueden ser utilizados para fines políticos de muy diversas formas: "fabricar tendencias, jugar con los hashtags, amplificar determinados contenidos, enviar spam a la oposición y atacar a periodistas" ${ }^{51}$. La identificación de los bots no resulta una tarea al alcance de cualquier usuario; y los intentos de desenmascararlos mediante técnicas sofisticadas siempre tendrán que competir con contramedidas diseñadas por quienes desarrollan y utilizan los bots al servicio de sus causas ${ }^{52}$.

\subsection{El peligro de la desinformación: las fake news}

Internet posibilita el acceso a todo tipo de fuentes de información, lo que habitualmente permite a sus usuarios contrastar de manera relativamente sencilla la veracidad de las noticias que reciben. No obstante, las dinámicas de acceso a la información en Internet y las redes sociales -caracterizadas por la inmediatez y la superficialidad-, se han mostrado un caldo de cultivo inmejorable para la difusión de noticias falsas o

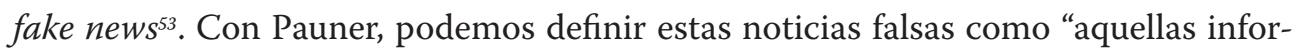
maciones ficticias o fraudulentas que se difunden a sabiendas de su inexactitud" ${ }_{54}$.

50. WOLLEY y HOWARD (2017) p. 6. Resulta inquietante constatar, como hacen los citados autores, que "una persona, o un pequeño grupo de personas, puede utilizar un ejército de bots políticos en Twitter a fin de crear la ilusión de que existe un consenso a gran escala sobre un determinado asunto".

51. PETIT (2018) p. 6. Y prosigue el mismo autor: "En manos de políticos poderosos y con recursos, estas herramientas automáticas pueden emplearse tanto para promover como para silenciar la comunicación y la organización entre ciudadanos, tanto en regímenes democráticos como autoritarios". RUBIO (2018) p. 216 subraya que la apariencia de mayoría o de amplio consenso que los bots pueden producir "genera un efecto arrastre o bandwagon, provocando la aceptación de aquellas ideas compartidas por una aparente mayoría”.

52. LAZER et al. (2018) p. 1095.

53. El concepto de fake news es marcadamente abierto. Con RUBIO NÚÑEZ (2018) p. 194, apuntamos que dicho concepto ha sido criticado "por resultar demasiado genérico; políticamente peligroso; indistinguible de otras formas de desinformación; vinculado a una idea demasiado simple que entiende la verdad como una imagen exacta de la realidad; porque el término no refleja el aspecto más relevante y peligroso del fenómeno: su capacidad de difusión; o, simplemente, por resultar un oxímoron". El mismo autor (2018) p. 198 subraya otras formas de referirse a las fake news como fenómenos de trastornos de la información: hechos alternativos, verdad a la carta, patologías informativas, manipulación, desinformación, intoxicación, propaganda, mentira y multimentira.

54. PAUNER (2018) p. 312; ÁLVARO (2018) p. 76 subraya de forma acertada la conexión existente entre fake news y economía de la atención. 
Tres son los elementos que suelen caracterizar a este tipo de mensajes pseudoinformativos: un titular impactante; una revelación que reafirma o indigna al receptor; y una apariencia legítima y fiable ${ }^{55}$. Ni que decir tiene que el fenómeno de las noticias falsas y la desinformación no es nuevo ${ }^{56}$; lo que es nuevo es el entorno comunicativo, que permite su difusión con una extensión y velocidad desconocidas hasta la fecha, multiplicando exponencialmente su efecto pernicioso ${ }^{57}$.

En un contexto mediático marcado por la infoxicación, los distintos emisores y prestadores de servicios compiten por la atención de los usuarios, y los contenidos llamativos, controvertidos o escabrosos se muestran idóneos para conseguir tan fin ${ }^{58}$. Con la libertad que otorga la desvinculación total o parcial de la realidad, las noticias falsas cuentan con una innegable ventaja competitiva en este contexto, lo que en parte explica su rápida difusión en el ámbito de las redes sociales e Internet ${ }^{59}$. Existen otras causas que permiten dar razón de la proliferación de noticias falsas en los entornos digitales: la ausencia de gatekeepers o watchdogs hace relativamente sencillo ponerlas a circular; el anonimato de la red facilita la impunidad del primer emisor; la tendencia hacia la polarización de las redes propicia su buena $\operatorname{acogida}^{60}$; el hecho de recibirlas de un contacto conocido que actúa como prescriptor les da una pátina de credibili$\operatorname{dad}^{61}$; y la superficialidad e inmediatez que caracterizan el debate en las redes hace infrecuente su confrontación con fuentes de información más fiables ${ }^{62}$.

55. AMORÓS (2018) pp. 65-66.

56. RODRÍGUEZ FERRÁNDIZ (2019) p. 2-4.

57. RUBIO NÚÑEZ (2018) pp. 198 y ss.

58. Como recuerdan VERSTRAETE et al. (2017) p. 25, la difusión de noticias falsas -y de otros contenidos polémicos- en las redes no beneficia exclusivamente a su creador, sino también y muy señaladamente a la propia red social, cuyos beneficios económicos dependen también de conseguir y mantener la atención de sus lectores. LAMBRECHT et al. (2018) p. 62 resumen esta posición ambivalente de las plataformas respecto del contenido más problemático que alojan preguntándose si las mismas son "mirones inocentes o cómplices oportunistas".

59. En el ecosistema de las redes sociales y la posverdad, "la comunicación se convierte en espectáculo, premiando los conceptos simples, los titulares engañosos, todo aquello que pueda llamar la atención", lo que supone un caldo de cultivo óptimo para la proliferación de las fake news. RUBIO NÚÑ̃Z (2018) p. 207.

60. LAZER et al. (2018) p. 1095.

61. PAUNER (2018) p. 303.

62. RUBIO NÚÑEZ (2018) p. 209. 
La puesta en circulación de fake news puede tener distintas finalidades: entretenimiento, adquisición de popularidad, lucro económico asociado al tráfico o manipulación de carácter político ${ }^{63}$. Independientemente de su finalidad, la noticia falsa distorsiona el debate público: de un lado, engaña temporal o indefinidamente a un conjunto de receptores; de otro, obliga a los receptores a los que no engaña a dedicar tiempo y recursos a combatir la desinformación ${ }^{64}$.

Dejando a un lado su recurso como mero entretenimiento o como fuente de ingresos, resulta particularmente alarmante su posible utilización como arma política en contextos especialmente sensibles, como períodos electorales, situaciones de crisis o escenarios de mayor inestabilidad o enfrentamiento social. De hecho, la generalización del término fake news a partir de 2016 está indisociablemente vinculada a dos procesos electorales celebrados en dicho año: las elecciones presidenciales norteamericanas que ganó Donald Trump y el referéndum sobre la permanencia de Reino Unido en la Unión Europea ${ }^{65}$. También ha comenzado a suscitar preocupación la posibilidad de injerencias extranjeras en la opinión pública de un país, mediante la propagación de noticias falsas dirigidas a sus ciudadanos a través de las redes socia$\operatorname{les}^{66}$.

Nunca hasta ahora los propagadores de bulos, medias verdades y puras mentiras habían contado con un canal tan poderoso como las redes sociales para hacer correr sus mensajes. Independientemente de la forma en que la desinformación haya de ser combatida, la preocupación por la calidad del debate democrático parece plenamente justificada. Y ello porque, como señala Pauner, la propagación indiscriminada de fake news afecta directamente a los fundamentos de las sociedades democráticas, "que se construyen sobre la presunción de que sus ciudadanos toman decisiones informadas en el momento de ir a votar" ${ }^{67}$.

63. Una tipología más detallada de las fake news propias de las redes sociales puede consultarse en: VERSTRAETE et al. (2017).

64. VARGO et al. (2018).

65. PARRA y OLIVEIRA (2018) p. 55. Entre las numerosas publicaciones sobre el impacto de las fake news en el proceso electoral estadounidense de 2016 destacamos la de ALLCOTT y GENTZKOW (2017) p. 212, conforme a la cual "durante la campaña electoral se generaron un total de 115 noticias falsas favorables al actual presidente de Estados Unidos que se compartieron en Facebook un total de 30 millones de veces, frente a las 41 fake news en beneficio de Hillary Clinton compartidas en 7,6 millones de ocasiones.

66. TORRES SORIANO (2017).

67. PAUNER (2018) p. 299. 


\subsection{El peligro de la atomización}

Como se ha apuntado con anterioridad, la existencia de una opinión pública libre presupone la interacción de los individuos en un ágora pública, común y compartida, donde exponer y contrastar libremente sus ideas. Si bien es cierto que la tecnología digital e Internet pueden facilitar la existencia de esa esfera pública común en el que compartir y contrastar distintas opiniones, también es verdad que su arquitectura puede fragmentar el espacio público en entornos atomizados e incomunicados ${ }^{68}$. Veamos cómo.

\subsubsection{El filtro burbuja}

Con la intención de ofrecer al usuario una experiencia de navegación adaptada a sus gustos y preferencias, las redes sociales tienden a presentarle aquellas realidades, informaciones y opiniones coincidentes con los intereses que ha mostrado en el pasado, o con los intereses de sus contactos más cercanos. En efecto, los algoritmos personalizan el entorno digital de cada internauta en base a sus gustos, con lo que terminan ofreciendo una visión muy sesgada de su entorno y de la realidad ${ }^{69}$. Pariser ha descrito tempranamente esta realidad, a la que denomina "filtro burbuja" -filter bubble-, y ha denunciado de forma preclara el dramático efecto que la misma puede tener para la solidez del debate público ${ }^{70}$.

Llevada a sus últimas consecuencias, la filter bubble supondría el acta de defunción del espacio público como entorno común y compartido -en el que todos los ciudadanos están expuestos a hechos, interpretaciones y opiniones relativamente homogéneos-, dando paso a una infinidad de espacios individualizados y customizados -microcomunidades autorreferenciales, las denomina Rubio ${ }^{71}$, perfectamente adaptados a las preferencias de cada usuario ${ }^{72}$. Esta desaparición de la esfera pública

68. Para una interesante contraposición entre los autores que sostienen que la personalización de la información "conlleva la desaparición del espacio público", y los que defienden que Internet "amplía la esfera pública”, véase: COTINO HUESO (2013) pp. 46-48.

69. CASTELLANOS (2019) p. 5.

70. PARISER (2011).

71. RUBIO (2018) p. 214.

72. Como señalan CANO-ORÓN y LLORCA-ABAD (2018) p. 111, "la idea de que Internet nos conecta con todo el mundo por igual, sin filtros y que ofrece una información plural, creando un espacio democrático, sencillamente no es real y es una interpretación ideológica interesada. La esfera pública digital está adaptada a cada usuario, es decir, pierde su característica de pública o general para pasar a ser muy individual". 
común, a su vez, daría lugar a un encastillamiento de las diferencias: "si el algoritmo suprime las fuentes diversas, e incluso contradictorias, de información -esto es, aquellas que retan nuestras convicciones personales- se corre el riesgo de que aumente hasta el extremo la separación de los diversos puntos de vista sociales, creando grupos sociales realmente divergentes"73.

\subsubsection{Las cámaras de resonancia}

El aislamiento en comunidades y entornos homogéneos -fruto del filtro burbujapuede hacer que los usuarios de las redes interactúen en echo chambers o cámaras de resonancia, donde en lugar de entrar en contacto con diferentes opiniones y cosmovisiones, se limiten a relacionarse con personas de posiciones similares a las propias ${ }^{74}$. Esta ausencia de contraste con ideas diferentes muy previsiblemente tendrá como consecuencia el refuerzo y la polarización de las opiniones, así como un incremento de la dificultad para comprender a quienes no piensan igual ${ }^{75}$.

Conforme a esta narrativa, la conversación racional sobre las cuestiones públicas -tan característica de la esfera pública democrática- será sustituida por un pluralismo agresivo, por una verdadera cacofonía digital, en la que cada grupo procurará imponer su opinión a los demás ${ }^{76}$.

Para relativizar los efectos nocivos de la atomización de la esfera pública, podría argüirse que la tendencia a rodearse de personas que comparten los puntos de vista propios es tan antigua como el ser humano mismo, con lo que no tiene mucho sentido alarmarse por el hecho de que en las redes sociales dicha tendencia se reproduzca. De un modo u otro, las echo chambers siempre han existido, y no han sido óbice al desarrollo de nuestras democracias. A lo anterior, no obstante, cabría oponer el hecho de que en los entornos previos a Internet la decisión de rodearse de personas con similares cosmovisiones era consciente, voluntaria y bien visible, mientras que en las redes sociales los filtros burbuja y las cámaras de resonancia a menudo se generan de

73. PAUNER (2018) p. 303.

74. SUNSTEIN (2003) p. 55.

75. En palabras de ÁLVARO (2018) p. 78, los filtros burbuja generan "una ordenación hemofílica en que somos segregados en grupos cerrados y solo en contacto con aquellos que piensan como nosotros, un entorno homogéneo y hecho a medida que funciona como una cámara de resonancia que amplifica nuestros prejuicios, gracias a la tendencia que tenemos a considerar como verdaderas aquellas informaciones que confirman nuestras creencias".

76. ARIAS MALDONADO (2016) p. 39. Como apunta VALLESPÍN (2015) p. 46, esta cacofonía puntualmente se convertirá en verdadero linchamiento al discrepante, en lo que se ha dado en llamar muy expresivamente shitstorms o shitshowers. 
forma inconsciente e imperceptible para el usuario. Así, los ciudadanos pueden tener la impresión de que están en contacto con personas y contenidos de todo tipo, cuando en realidad una decisión algorítmica restringe sus interacciones a un círculo de personas muy homogéneo, con el consiguiente empobrecimiento de su perspectiva y del propio debate público ${ }^{77}$.

La atomización del espacio público resultante de la paulatina personalización de las redes sociales constituye un importante envite para la pervivencia de la democracia. Como recuerda Álvaro, "la democracia solo funciona si los ciudadanos son capaces de pensar más allá del estrecho campo definido por sus propios intereses. Para que esto se produzca, necesitamos una visión compartida del mundo en el que cohabitamos. Los filtros burbuja [y las cámaras de resonancia] nos empujan en la dirección contraria, creando la impresión de que aquello que cae bajo nuestro interés personal es lo único que existe"78.

\section{La necesaria respuesta multinivel a los riesgos apuntados}

Los peligros previamente apuntados para el pluralismo, la diversidad, la transparencia, la veracidad de la información y la comunalidad de la esfera pública no son ineludibles. Desde diferentes ámbitos vienen proponiéndose posibles soluciones a cada uno de estos desafíos, tendentes a convertir las redes sociales de Internet en aliados del debate público y la democracia, maximizando sus potencialidades al servicio de la participación y minimizando sus innegables externalidades negativas.

La implementación de estas soluciones no resulta sencilla por diversos motivos. A la velocidad del avance tecnológico, y a la íntima conexión de la comunicación a través de las redes sociales con el ejercicio de derechos fundamentales, se suma la imposibilidad de atribuir a un único agente la responsabilidad por los problemas que un mal uso de las redes sociales genera. En efecto, los peligros que las redes suponen para la esfera pública son un "problema de muchas manos" - a many hands problem $^{79}$-, producidos por la confluencia de decisiones de un conjunto de personas -programadores, empresas, creadores de contenido, usuarios-, cuya responsabilidad individual es muy limitada. Ello determina que las respuestas tendentes a construir y preservar una esfera pública democrática no puedan ser unilaterales, ya que ninguno de los agentes implicados puede por sí mismo resolver los desafíos que las redes plantean.

77. CASTELLANOS (2019) p. 9.

78. ÁLVARO (2018) p. 78.

79. La expresión "the problem of many hands" para caracterizar este tipo de problemas la debemos a THOMPSON (1980). 
El "problema de las muchas manos" exige pues soluciones colaborativas, "de muchas manos", en las que se impliquen de forma conjunta y responsable los poderes públicos, la industria de Internet, los usuarios de las redes y toda la sociedad en su conjunto.

A continuación, sin ánimo de exhaustividad, ofrecemos una cata de soluciones que han sido propuestas o ensayadas hasta la fecha para dar respuesta a las amenazas previamente apuntadas. Las medidas que se presentan distan mucho de constituir un catálogo cerrado o definitivo; se trata, más bien, de unas primeras aproximaciones de carácter exploratorio o tentativo a una serie de desafíos que, según parece, va a interpelarnos durante los próximos lustros.

\subsection{Respuestas desde los poderes públicos y el Derecho}

Los poderes públicos tienen como principal misión la defensa de los derechos de los ciudadanos y la promoción de los intereses públicos. En este sentido, su responsabilidad en la promoción de una esfera pública abierta y plural es irrenunciable.

En defensa de la transparencia, el Poder legislativo podría, en primer lugar, imponer ciertas obligaciones de transparencia a los servicios que trabajan mediante algoritmos, en la línea del derecho a obtener una explicación de las decisiones tomadas por un algoritmo reconocido en el artículo 25 del Reglamento General de Protección de Datos $^{80}$. Junto con ello, se podría actualizar la normativa relativa a la publicidad encubierta, la publicidad política y la publicidad electoral, a fin de garantizar que las redes sociales no sean empleadas como canales de propaganda política sin el consentimiento expreso del usuario ${ }^{81}$. En similar sentido, podría exigirse a los prestadores la publicación de listas de anunciantes, cuando los mismos persigan una determinada agenda política o ideológica, más allá de lo puramente comercial.

Por lo que se refiere a la lucha contra la atomización de la esfera pública, los esfuerzos de los poderes públicos deberían dirigirse al establecimiento de canales públicos de calidad, con una presencia significativa en las redes sociales -canales de Youtube,

80. DIGNUM (2017) ha propuesto los ART principles (acrónimo de Accountability, Responsibility y Transparency - rendición de cuentas, responsabilidad y transparencia), como principios que podrían regir el funcionamiento de los algoritmos y la inteligencia artificial.

81. De forma casi unánime, la doctrina doméstica ha criticado la reciente reforma de la Ley Orgánica 5/1985, del Régimen Electoral General, que en su nuevo artículo 58.bis permite a los partidos políticos utilizar las redes sociales para realizar perfiles políticos y enviar publicidad electoral a los potenciales votantes. El Defensor del Pueblo español ha presentado un recurso de inconstitucionalidad sobre el particular, pendiente de resolución en el momento en el que se escriben estas páginas. El texto del recurso puede consultarse en: https://www.defensordelpueblo.es/wp-content/ uploads/2019/03/Demanda_Recurso_2019.pdf. 
perfiles de Facebook o de Twitter, etc. Estos medios públicos deberían convertirse en verdaderos referentes de pluralismo e interacción entre los diferentes grupos sociales existentes en una sociedad, actuando de contrapeso a la atomización tantas veces existente en los entornos digitales ${ }^{82}$.

Íntimamente unido a lo anterior, los poderes públicos deberían promover el pluralismo y la diversidad cultural. Para ello, en primer lugar, es oportuno aplicar las leyes de defensa de la competencia con contundencia y sin complejos. También pueden imponerse -ya se está haciendo- ciertas obligaciones de financiación de obra europea o cuota de pantalla a los prestadores que tienen una responsabilidad editorial sobre los contenidos, como los prestadores de televisión a la carta en Internet -Netflix, HBO, Amazon Premium ${ }^{83}$. Más allá de estas previsiones coercitivas, sería muy recomendable diseñar políticas públicas promocionales y de fomento, con el fin de incentivar a los agentes privados a tomar decisiones -empresariales o personales- orientadas a salvaguardar el pluralismo y la diversidad, mediante campañas de sensibilización, subvenciones, coproducciones, etc.

Por último, y en relación con las fake news, algunos países de nuestro entorno están ensayando leyes orientadas a luchar contra la desinformación en Internet, imponiendo a las redes sociales obligaciones de transparencia y el establecimiento de mecanismos de recepción de quejas y retirada de contenido ilegal en plazos de tiempo muy cortos. Así, en Alemania, la ley NetzDG obliga a las redes con más de dos millones de usuarios alemanes a retirar en menos de 24 horas aquellos contenidos manifiestamente ilegales, y en menos de una semana los que son ilegales. Los incumplimientos de las previsiones legales pueden alcanzar multas de hasta 50 millones de euros $^{84}$. También resulta interesante la norma contra la manipulación de la información recientemente aprobada en Francia, que despliega sus efectos durante los tres meses previos al período electoral, en los cuales se habilita al Poder Judicial a bloquear el acceso a informaciones manifiestamente falsas o inexactas que tengan como

82. IBRUS y ROHN (2016) pp. 10-11.

83. Sobre el particular, resulta de interés: DONDERS et al. (2018).

84. Ley de Mejora de la Aplicación de la Ley en las redes sociales (Entwurf eines Gesetzes zur Verbesserung der Rechtsdurchsetzung in sozialen Netzwerken), en vigor desde el 1 de octubre de 2017. La ley NetzDG también obliga a las redes a publicar un informe semestral sobre la gestión de estas reclamaciones. A título ejemplificativo, puede consultarse el informe publicado por Google en relación con su servicio Youtube, disponible en la siguiente dirección: https://transparencyreport. google.com/netzdg/youtube?hl=es. 
finalidad alterar los resultados del proceso electoral ${ }^{85}$. Si bies es pronto para valorar la utilidad práctica de estas experiencias, lo cierto es que a priori las soluciones que ofrecen plantean dudas en cuanto a su proporcionalidad y su efectividad. Por lo que a la proporcionalidad se refiere, y habida cuenta de los perfiles borrosos de las noticias falsas, su persecución corre el riesgo de rozar la censura y debilitar el debate público en Internet ${ }^{86}$. En cuanto a la efectividad de la normativa, el hecho de que muchas veces estas noticias falsas sean compartidas por aplicaciones de mensajería como Whatsapp - sobre cuyas conversaciones los titulares del servicio no tienen posibilidad de actuación- puede convertir las previsiones legales en papel mojado. Otra posible respuesta legal para combatir las fake news estribaría en ampliar las condiciones de legitimación activa y pasiva en la legislación relativa al derecho al honor, a fin de que más personas pudieran interponer las acciones jurídicas necesarias para exigir la retirada de determinados contenidos ${ }^{87}$. En sentido similar, podría desarrollarse normativamente la dimensión institucional del derecho a la información, configurando la veracidad de la información como un verdadero interés público. De este modo, la veracidad de ciertas informaciones podría esgrimirse como límite al ejercicio de los derechos comunicativos -como actualmente lo son la seguridad nacional o la salud pública- de forma independiente, y no vinculada siempre al derecho al honor o la propia imagen de alguien. Este desarrollo normativo permitiría ampliar la legitimación de ciudadanos y poderes públicos a la hora de combatir las noticias falsas que enturbian la opinión pública con informaciones no veraces, aunque las mismas no afecten directamente al honor o la propia imagen de una persona o institución concreta. Finalmente, qué duda cabe, el mantenimiento de unos medios de comunicación públicos rigurosos y plurales serviría también como antídoto o cortafuegos frente a la difusión de las noticias falsas, ofreciendo a la ciudadanía una fuente acreditada de información veraz.

Junto con lo previamente apuntado, los poderes públicos deben protagonizar un decidido esfuerzo de alfabetización digital de los usuarios de las redes, para que sean conscientes de los riesgos asociados a su mal uso y asuman las responsabilidades que

\footnotetext{
85. Ley de lucha contra la manipulación de la información (LOI n 2018-1202 du 22 décembre 2018 relative à la lutte contre la manipulation de l'information).
}

86. NAVARRO (2018).

87. LAZER et al. (2018) p. 1096. 
les corresponden ${ }^{88}$. Esta alfabetización mediática puede canalizarse a través de las más variadas formas de comunicación y promoción: planes de educación en centros escolares; programas de formación en el uso de las tecnologías para mayores; certámenes, premios y concursos orientados a la sensibilización; campañas publicitarias institucionales y un largo etcétera.

Como vehículo para canalizar todas estas actuaciones públicas, podría resultar oportuna la creación de una agencia o administración independiente -de ámbito estatal o europeo- cuya finalidad básica fuera supervisar funcionamiento de los algoritmos y el desarrollo de la inteligencia artificial, a fin de garantizar que dichas herramientas tecnológicas sean respetuosas con los principios y valores constitucionales ${ }^{89}$. Dicha administración, de carácter especializado e independiente, podría asumir potestades de desarrollo reglamentario, fomento, supervisión y sanción.

\subsection{Respuestas tecnológicas y de mercado}

Además de los esfuerzos provenientes de los poderes públicos, la defensa de la esfera pública debe contar con la colaboración de los propios agentes del sector, que mediante fórmulas de autorregulación o corregulación pueden contribuir decisivamente a configurar sus entornos como espacios respetuosos con los derechos de sus usuarios y los intereses públicos previamente descritos.

En relación con la transparencia, las redes sociales deberían comprometerse en primer lugar a combatir la propaganda política encubierta: bien excluyendo este tipo de publicidad de sus servicios; bien señalizando la publicidad de carácter político o ideológico, a fin de hacerla fácilmente reconocible por sus usuarios. Además, las redes deberían invertir recursos personales y materiales en detectar y luchar contra la actividad de bots y trolls, que distorsionan de forma encubierta el debate público difundiendo propaganda computacional.

88. El apartado 4.e de la Declaración Conjunta sobre Libertad de Expresión y Noticias Falsas, Desinformación y Propaganda de la ONU, la OSCE, la OEA y la CADHP, de 3 de marzo de 2017, apunta en esta dirección, señalando que los Estados "deberían adoptar medidas para promover la alfabetización digital y mediática, entre otras cosas, incluyendo estos temas [noticias falsas, desinformación y propaganda] en los planes de estudio académicos regulares e involucrando a la sociedad civil y a otras partes interesadas para la concienciación sobre estas cuestiones".

89. La creación de un organismo independiente con competencias en materia de algoritmos y de inteligencia artificial ha sido propuesta, entre otros, por CERRILLO (2019) pp. 23-24, si bien la propuesta de este autor parte de la preocupación por el creciente uso que de estas herramientas hacen las administraciones públicas. 
Una segunda línea de actuación debería ir encaminada a mitigar el filtro burbuja, diseñando sus interfaces y programando sus algoritmos de forma que los usuarios estén expuestos a informaciones y opiniones que contrasten con sus propios puntos de vista, particularmente en relación con contenido de índole política ${ }^{90}$. Ello podría hacerse de forma evidente, ofreciendo al usuario opciones como "ver opiniones diferentes"; o bien de forma menos palmaria, intercalando ocasionalmente titulares o enlaces a medios de orientación distinta a la del usuario ${ }^{91}$. En sentido similar, y a fin de promover el pluralismo y la diversidad, las redes podrían añadir a sus algoritmos un factor tendente a promover contenido de carácter más alternativo, local o minoritario, como contrapeso a la estandarización de los contenidos que el network effect puede generar. No se nos escapa que las dos medidas previamente apuntadas resultan costosas para la red social, perturbando los hábitos de navegación de sus usuarios. Sin embargo, la importancia del pluralismo y la diversidad deberían ser causas suficientes para asumir dichos costes, que no serán excesivos si se explica bien a los usuarios los motivos que subyacen a la política de pluralismo y diversidad de la red social.

Por lo que respecta a las fake news, se han propuesto diferentes medidas para mitigar su difusión y su impacto en el ámbito de las redes sociales, algunas de las cuales están siendo ya ensayadas por los principales prestadores de servicios ${ }^{92}$. Básicamente, las estrategias constan de tres momentos: revisión de la noticia (fact checking); decisión editorial sobre el contenido que se califica como poco fiable o fake; y posible penalización a la fuente poco fiable ${ }^{93}$. El fact checking puede realizarse por distintos agentes: los propios usuarios del servicio, un equipo de expertos integrados en la red social, una organización externa, o incluso un algoritmo ${ }^{94}$. Una vez que se determina

90. LAZER et al. (2018) p. 1096.

91. HELBERGER et al. (2018) pp. 9-10.

92. A título ejemplificativo, puede consultarse la política de Facebook en: Hard Questions: What's Facebook's Strategy for Stopping False News?, 23 de mayo de 2018. Disponible en: https://newsroom. fb.com/news/2018/05/hard-questions-false-news/ (última visita: 1.04.2019). Por lo que se refiere a Google, desde 2017 cuenta con una herramienta de verificación de hechos, como explica su blog oficial en España: La verificación de hechos está disponible en Google Search y Google News en todo el mundo, 7 de abril de 2017. Disponible en: https://espana.googleblog.com/2017/04/la-verificacionde-hechos-esta.html?m=1 (última visita: 1.04.2019).

93. En paralelo a las estrategias de fact checking, algunos servicios de mensajería como Whataspp ha limitado el número de reenvíos que puede hacerse de un determinado mensaje, a fin de poner cierto coto a la difusión masiva de mensajes y noticias.

94. Cada una de estas opciones tiene sus pros y sus contras en términos de objetividad, fiabilidad y sostenibilidad económica. Para un análisis más detenido de estas posibilidades, véase: PARRA y OLIVEIRA (2018) pp. 66 y ss. 
que un contenido es erróneo, la red social debe decidir cómo responder frente al mismo: puede eliminarlo, o bien señalizarlo como dudoso, poco contrastado o falso ${ }^{95}$. Por último, la red social puede penalizar de diferentes formas a aquellas fuentes -usuarios particulares, medios de comunicación- que hayan difundido contenido falso, a fin de prevenir futuras fake news de la misma fuente ${ }^{96}$. Sensu contrario, también se ha sugerido que las redes y buscadores premien con una mayor visibilidad a los usuarios, canales o cabeceras con contenido habitualmente contrastado, si bien dicha opción no está exenta de amenazas para el pluralismo y la diversidad, como ha alertado acertadamente Dutton ${ }^{97}$.

A todo lo anterior es imprescindible sumar un decidido esfuerzo de las redes sociales por crear las condiciones en las cuales sus usuarios puedan hacer un uso cívico y responsable de sus plataformas ${ }^{98}$. Estas condiciones, cuyo fin último es el empoderamiento del usuario, revisten un carácter ciertamente heterogéneo y dinámico: desde el establecimiento de condiciones de uso transparentes, pasando por políticas de protección de datos garantistas o campañas de alfabetización digital, hasta la creación de sistemas de denuncia de contenidos ilegales, nocivos o inexactos, que establezcan procedimientos de control y retirada efectivos y garantistas.

\subsection{Respuestas de la comunidad digital}

El protagonismo de los usuarios de las redes en la generación y difusión de contenido hace imprescindible contar con ellos para establecer y preservar una esfera pública verdaderamente democrática. Un usuario responsable no debería actuar en las redes sociales como un mero consumidor de contenido, sino como un ciudadano titular de derechos y deberes, consciente de la importancia de sus decisiones personales para la existencia de un ecosistema mediático saludable y de una conversación pública de calidad $99^{9}$

95. PAUNER (2018) p. 317 apuesta por esta opción, señalando que "el control de contenidos debe finalizar con un etiquetado que sirva de aviso al usuario sobre la baja o nula calidad de la noticia dejando a aquel la libertad de decidir por sí mismo”.

96. Dicha penalización puede consistir en una pérdida de relevancia en el listado de resultados; en la exclusión de los programas de monetización por visitas; o en el cierre del canal o del perfil. Sobre el particular, VERSTRAETE et al. (2017) p. 27; ÁLVARO (2018) p. 79.

97. DUTTON (2019).

98. HELBERGER et al. (2018) pp. 3-4 apuntan diferentes maneras de empoderar a los usuarios mediante decisiones sobre la arquitectura de las plataformas.

99. FUENTE COBO et al. (2014) p. 92. 
En cuanto a los riesgos asociados a la opacidad, el ciudadano podría, en primer lugar, exigir a los responsables políticos la imposición de exigencias de transparencia a las redes. Adicionalmente, está en su mano sancionar con sus decisiones individuales a las redes que abusen de sus datos o realicen propaganda no consentida, así como a los anunciantes o partidos que recurran a dichas estrategias, una vez que las mismas sean desveladas.

Por lo que se refiere a la atomización y al pluralismo, conscientes de la posibilidad de terminar encerrados en filtros burbuja y cámaras de resonancia, los usuarios podrían premiar aquellas redes que les expusieran a contenidos diferentes, o utilizar las herramientas desarrolladas por las plataformas para tal fin. Nunca ha sido tan fácil acceder y compartir contenido de fuentes de información tan variadas ideológicamente, lo que constituye una oportunidad inmejorable de contrastar los propios puntos de vista y difundir informaciones de diferentes sesgos cuando se estimen interesantes. Además, el hecho de acceder, compartir o evaluar contenido diverso y variado implica directamente exponerse en el futuro a fuentes de información más heterogéneas; e, indirectamente, influir en el tipo de contenido que se presenta a otros usuarios con los que se mantienen vínculos en las redes ${ }^{100}$.

Finalmente, los usuarios de las redes deberían desarrollar un cierto espíritu crítico ante las noticias que reciben, para no tomar por buena cualquier noticia que les llegue, ni difundir indiscriminadamente noticias de cuya veracidad tengan fundadas sospechas ${ }^{101}$. En este sentido, existen diferentes plataformas de fact checking que permiten a un usuario conocer si ciertas noticias que se difunden en las redes sociales tienen una base real o son fake news, como PolitiFact, Snopes, o la española Maldito Bulo $^{102}$. Como ya se ha apuntado, algunas redes han habilitado sistemas para involucrar al usuario en el etiquetado de contenido, de forma que pueden calificar los contenidos según su propio criterio, decidiendo si se les otorga o no credibilidad $^{103}$.

100. HELBERGER et al. (2018) p. 9.

101. VAN DIJCK y POELL (2013) pp. 6-8 analizaron tempranamente cómo la "popularidad" se configura como uno de los principios básicos de la lógica de las redes. Así, compartir o dar un like a un contenido en una red social contribuye a multiplicar su impacto y su credibilidad.

102. Sobre el particular, resulta de interés el reciente estudio acerca de las herramientas de fact checking en español de VIZOSO y VÁZQUEZ-HERRERO (2019). La Comunicación de la Comisión "La lucha contra la desinformación en línea: un enfoque europeo" (COM/2018/236 final) recomienda a los Estados apoyar financieramente este tipo de iniciativas de verificación de la información que circula por las redes sociales.

103. En cualquier caso, como señalan PARRA y OLIVEIRA (2018) p. 67 este etiquetado de noticias por los usuarios no está exento de problemas, ya que también "es susceptible de ser manipulado por grupos de personas que promuevan las mismas noticias falsas". 


\section{Conclusiones}

La esfera pública, considerada como el espacio en el que la ciudadanía discute los asuntos de interés general, constituye un elemento fundamental en una democracia. En las sociedades contemporáneas, las redes sociales forman parte muy señalada de esta esfera, toda vez que canalizan gran parte del debate político y del acceso a la información y a la opinión sobre cuestiones de interés público.

Para constituir un entorno idóneo de intercambio de ideas, que permita la correcta conformación de la opinión pública y la voluntad general, la esfera pública debe reunir algunas características, entre las que hemos destacado el pluralismo, la diversidad, la transparencia, la veracidad de las informaciones y la comunalidad.

Como se ha tenido ocasión de exponer, cada una de estas características puede ser amenazada por la configuración actual del entorno mediático digital. En efecto, el ecosistema de las redes sociales puede hacer que la esfera pública se convierta en un entorno opaco, atomizado y monocromo, donde sea cada vez más difícil distinguir la información veraz de las fake news.

En este contexto, resulta urgente en primer lugar que desde las diferentes ciencias sociales se estudie con detenimiento los riesgos aquí descritos, y se arroje luz sobre su incidencia real. Esta investigación multidisciplinar -que ya se ha comenzado, como acreditan los abundantes trabajos aquí citados- es condición previa para adoptar soluciones razonables y proporcionadas, evitando caer tanto en la ingenuidad tecnófila de quien no ve nunca ningún problema, como en el pesimismo tecnófobo de quien da por ya cumplido cualquier negativo augurio, recurriendo a soluciones sobredimensionadas e intempestivas que ahogan el avance científico y las libertades individuales. Una vez determinada la magnitud de cada riesgo y su impacto real en la esfera pública, se deberían ensayar medidas que mitigaran dichos efectos negativos con el mínimo coste para los derechos comunicativos y la libertad de empresa. En esta línea, se han planteado diferentes soluciones y medidas que podrían ponerse en marcha por parte de todos los agentes implicados en el uso de las redes: los usuarios, los responsables de las redes sociales y los poderes públicos. Habida cuenta de la naturaleza colaborativa y descentralizada de las redes sociales, las soluciones a los problemas planteados deben ser también compartidas, en un esfuerzo común de poderes públicos, empresas y ciudadanos por preservar un espacio público verdaderamente democrático. Nos va mucho en ello. 


\section{Referencias bibliográficas}

ALLCOTT, Hunt y GENTZKOW, Matthew (2017): "Social media and fake news in the 2016 election". En Journal of Economic Perspectives, año $31 \mathrm{~N}^{\circ} 2$, pp. 211-236. Disponible en: https://doi.org/10.1257/jep.31.2.211 [Fecha de consulta: 1 de junio de 2020].

ÁLVARO, Sandra (2018): "La esfera pública en la era de la hipermediación algorítmica: noticias falsas, desinformación y la mercantilización de la conducta”. En Hipertext.net, No 17, pp. 74-82. Disponible en: https://doi.org/10.310o9/hipertext. net.2018.i17.07 [Fecha de consulta: 1 de junio de 2020].

AMORÓS, Marc (2018): Fake News. La verdad de las noticias falsas (Barcelona, Plataforma Editorial).

ARIAS MALDONADO, Manuel (2016): "La digitalización de la conversación pública: redes sociales, afectividad política y democracia”. En Revista de Estudios Políticos, No 173, pp. 27-54. Disponible en: http://dx.doi.org/10.18042/cepc/rep.173.01 [Fecha de consulta: 1 de junio de 2020].

BARBER, Benjamín (2004): Democracia fuerte (Editorial Almuzara: Córdoba).

BOIX PALOP, Andrés (2016): "La construcción de los límites de la libertad de expresión en las redes sociales". En Revista de Estudios Políticos, No 173, pp. 55-112. Disponible en: http://dx.doi.org/10.18042/cepc/rep.173.02 [Fecha de consulta: 1 de junio de 2020].

BOCANEGRA REQUENA, José Manuel (2012): "El derecho del ciudadano a una comunicación audiovisual plural y transparente". En Noticias de la Unión Europea, No 329 , pp. 3-10.

BOYD, Danah M. y ELLISON, Nicole B. (2007): "Social Network Sites: Definition, History, and Scholarship". En Journal of Computer-Mediated Communication, No 13, pp. 210-230. Disponible en: http://dx.doi.org/10.1111/j.1083-6101.2007.00393.x [Fecha de consulta: 1 de junio de 2020].

BRADSHAW, Samantha y HOWARD, Philip N. (2017): Troops, trolls and Troublemakers: A global inventory of Organized Social Media manipulation. Working paper 2017-12 (Oxford, Computational Propaganda Research Project).

CANO-ORÓN, Lorena y LLORCA-ABAD, Germán (2018): "La configuración invisible del espacio digital: el caso de Facebook". En Observatorio (OBS*), año $12 \mathrm{~N}^{\circ} 3$, pp. 106-121. 
CASTELLANOS CLARAMUNT, Jorge (2019): "La democracia algorítmica inteligencia artificial, democracia y participación política”. En Revista General de Derecho Administrativo, No 50 , pp. 1-32.

CERRILLO I MARTÍNEZ, Agustí (2019): “Com obrir les caixes negres de les administracions públiques? Transparència i rendició de comptes en l'ús dels algoritmes". En Revista Catalana de Dret Públic, No 58, pp. 13-28.

CONSTANT, Benjamin (1989): Escritos políticos (Madrid: Centro de Estudios Constitucionales).

COTINO HUESO, Lorenzo (2013): "La selección y personalización de noticias por el usuario de las nuevas tecnologías". En COTINO, L (dir): Libertad de expresión e información en Internet (Madrid: Centro de Estudios Políticos y Constitucionales), pp. 41-56.

DIGNUM, Virginia (2017): "Responsible Artificial Intelligence: Designing AI for $\mathrm{Hu}-$ man Values". En ITU Journal: ICT Discoveries, No 1 (esp.), pp. 1-8.

DONDERS, Karen et al. (2018): Obligations on on-demand audiovisual media services providers to financially contribute to the production of European works. An analysis of European Member States' practices (Bruselas: VUB).

DUTTON, William H. et al. (2017): "Social Shaping of the Politics of Internet Search and Neworking: Moving Beyond Filter Bubbles, Echo Chambers, and Fake News". En Quello Center Working Paper No 2944191 (Michigan: Quello Center), pp. 1-26.

DUTTON, William H. (2019): "The New News Strategy? How the Panic Over Fake News Could Undermine the News". Billdutton.me [blog], 5-02-2019. Disponible en: https://billdutton.me/2019/02/05/the-new-news-strategy-how-the-panicover-fake-news-could-undermine-the-news/ [Fecha de consulta: 1 de junio de 2020].

FUENTE COBO, Carmen et al. (2014): "Las audiencias activas en la regulación de los medios: la dialéctica consumidor-ciudadano en España y México". En Comunicar, $\mathrm{n}^{\circ}$ 43, pp. 91-99. Disponible en: http://dx.doi.org/10.3916/C43-2014-09 [Fecha de consulta: 1 de junio de 2020].

HABERMAS, Jurgen (2002): Historia crítica de la opinión pública (México: Gustavo Gili).

HELBERGER, Natali (2018): "Challenging Diversity - Social Media Platforms and a New Conception of Media Diversity”. En Digital Dominance. The Power of Google, Amazon, Facebook, and Apple (Nueva York: Oxford University Press), pp. 153-175. 
HELBERGER, Natali et al. (2018): "Governing online platforms: from contested to cooperative responsibility”. En The Information Society, año $34 \mathrm{~N}^{\circ} 1$, pp. 1-14. Disponible en: https://doi.org/10.1080/01972243.2017.1391913 [Fecha de consulta: 1 de junio de 2020].

IBRUS, Indrek y ROHN, Ulrike (2016): "Sharing killed the AVMSD star: the impossibility of European audiovisual media regulation in the era of the sharing economy". En Internet Policy Review, año $5 \mathrm{~N}^{\circ} 2$, pp. 1-16. Disponible en: https://doi. org/10.14763/2016.2.419 [Fecha de consulta: 1 de junio de 2020].

INTRONA, Lucas D. y NISSENBAUM, Helen (200o): "Shaping the web: Why the politics of Search Engines matters". En Information Society, No 16, pp. 169-185.

KADUSHIN, Charles (2013): Comprender las redes sociales: teorías, conceptos y hallazgos (Madrid: Centro de Investigaciones Sociológicas).

KALOGEROPOULOS, Antonis y NEWMAN, Nic (2018): I saw the news on Facebook - Digital News Project 2017 (Oxford: Reuters Institute - Universidad de Oxford).

KEEN, Andrew (2015): The Internet is not the answer (London: Atlantic Books).

LAMBRECHT, Ingrid et al. (2018): "Platforms and commercial communications aimed at children: a playground under legislative reform?" En International Review of Law, Computers and Technology, año $32 \mathrm{~N}^{\circ}{ }_{1}$, pp. 58-79. Disponible en: https:// doi.org/10.1080/13600869.2018.1443378 [Fecha de consulta: 1 de junio de 2020].

LAZER, David M. J. et al. (2018): “The science of fake news”. En Science, № 359 (6380), pp. 1094-1096. Disponible en: https://doi.org/10.1126/science.aa02998 [Fecha de consulta: 1 de junio de 2020].

LÓPEZ GARCÍA, Guillermo (2016): "Nuevos y viejos liderazgos: la campaña de las elecciones generales españolas de 2015 en Twitter”. En Comunicación y sociedad, año $29 \mathrm{~N}^{\circ}$ 3, pp. 149-167. Disponible en: https://doi.org/10.15581/o03.29.3. sp.149-167 [Fecha de consulta: 1 de junio de 2020].

MANIN, Bernard (1998): Los principios del gobierno representativo (Madrid: Alianza Editorial).

MANSBRIDGE, Jane J. (1992): “A deliberative theory of interest representation”. En The politics of interest (Oxford: Westview Press), pp. 32-57.

MONZÓN, Cándido (2008): "El hombre espectador en la cultura de masas. Opinión pública y medios de comunicación”. En CAPELLÁN, G. (Ed.) Opinión pública. Historia y presente (Madrid: Trotta), pp. 207-225. 
MUÑOZ-ALONSO, Alejandro (1990): “Génesis y aparición del concepto de opinión pública”. En Opinión pública y comunicación política (Madrid: Eudema), pp. 2383.

NAVARRO, Pedro A. (2018): "Fake news y censura". En El siglo de Europa, № 1230, pp. 1-8.

PARISER, Eli (2011): The filter Bubble: What the Internet is hidden from you (Nueva York: Penguin Press).

PARRA VALERO, Pablo y OLIVEIRA, Lídia (2018): "Fake news: una revisión sistemática de la literatura”. En Observatorio $\left(\mathrm{OBS}^{*}\right), \mathrm{N}^{\circ}$ 1(extra), pp. 54-78.

PASQUALE, Frank (2015): The Black Box Society (Cambridge: Harvard University Press).

PAUNER CHULVI, Cristina (2018): "Noticias falsas y libertad de expresión e información. El control de los contenidos informativos en la Red". En Teoría y Realidad Constitucional, No 41, pp. 297-318. Disponible en: https://doi.org/10.5944/ trc.41.2018.22123 [Fecha de consulta: 1 de junio de 2020].

PÉREZ-DÍAZ, Víctor (1997): La esfera pública y la sociedad civil (Madrid: Taurus).

PETIT, Martí (2018): “Por una crítica de la razón algorítmica. Estado de la cuestión sobre la inteligencia artificial, su influencia en la política y su regulación”. En Quaderns del CAC, $\mathrm{N}^{\circ} 44$, pp. 1-15.

PETTIT, Philip (2001): A Theory of Freedom: From the Psychology to the Politics of Agency (Oxford: Oxford University Press, 2001).

RALLO LOMBARTE, Artemi (200o): Pluralismo informativo y Constitución (Valencia: Tirant lo Blanch).

DEL REY MORATÓ, Javier (2007): Comunicación politica, Internet y campañas electorales. De la teledemocracia a la ciberdemocracia (Madrid: Tecnos).

RODRÍGUEZ FERRÁNDIZ, Raúl (2019): "Postverdad y fake news en comunicación política: breve genealogía”. En El profesional de la información, № 28.

RODRÍGUEZ URIBES, José Manuel (1999): Opinión pública. Concepto y modelos históricos (Marcial Pons: Barcelona).

ROS-MARTIN, Marcos (2009): "Evolución de los servicios de redes sociales en internet”. En El profesional de la información, No 5, pp. 552-557. Disponible en: http://dx.doi.org/10.3145/epi.2009.sep.10 [Fecha de consulta: 1 de junio de 2020]. 
RUBIO NÚÑEZ, Rafael (2018): "Los efectos de la posverdad en la democracia". En Revista de Derecho Político, № 103, pp. 191-228. Disponible en: https://doi. org/10.5944/rdp.103.2018.23201 [Fecha de consulta: 1 de junio de 2020].

SARTORI, Giovanni (1988): Teoría de la democracia (Madrid: Alianza Editorial).

DE LA SIERRA, Susana y GONZÁLEZ BOTIJA, Fernando (2012): "La cultura en la Ley General de la Comunicación Audiovisual". En Noticias de la Unión Europea, $\mathrm{N}^{\circ}$ 329, pp. 11-28.

SOLOZÁBAL ECHEVARRÍA, Juan José (2018): "La libertad de expresión, reconsiderada”. En Revista General de Derecho Constitucional, № 27, pp. 1-4.

SUÁREZ-GONZALO, Sara (2018): “Tus likes ¿tu voto? Explotación masiva de datos personales y manipulación informativa en la campaña electoral de Donald Trump a la presidencia de EEUU 2016". En Quaderns del CAC, No 44, pp. 27-36.

SUNSTEIN, Cass R. (2003): República.com: Internet, democracia y libertad (Barcelona: Paidós).

THOMPSON, Dennis F. (1980): "Moral responsibility of public officials: The problem of many hands". En The American Political Science Review, año $74 \mathrm{~N}^{\circ} 4$, pp. 905-916. Disponible en: https://doi.org/10.2307/1954312 [Fecha de consulta: 1 de junio de 2020].

TORRES SORIANO, Manuel (2017): Hackeando la democracia: operaciones de influencia en el ciberespacio. Documento Opinión 66/2017 (Madrid: Instituto Español de Estudios Estratégicos).

VALLESPÍN OÑA, Fernando (2003): "Un nuevo espacio público: la democracia mediática". En Teoría política: poder, moral, democracia (Madrid: Alianza Editorial), pp. 462-477.

VALLESPÍN OÑA, Fernando (2015): "La gestión de la democracia en el entorno digital. Política y nuevas redes”. En Telos: Cuadernos de comunicación e innovación, No 100 , pp. 45-48.

VAN DIJCK, José y POELL, Thomas (2013): "Understanding social media logic". En Media and Communication, $\mathrm{N}^{\circ} 1(1)$, pp. 2-14. Disponible en: https://doi. org $/ 10.12924 / \mathrm{mac} 2013.01010002$ [Fecha de consulta: 1 de junio de 2020].

VARGO, CHRIS J. et al. (2018): "The agenda-setting power of fake news: A big data analysis of the online media landscape from 2014 to 2016". En New Media \& Society, $\mathrm{N}^{\circ}$ 2o(5), pp. 2028-2049. Disponible en: https://doi.org/10.1177/1461444817712086 [Fecha de consulta: 1 de junio de 2020]. 
VERSTRAETE, Mark et al. (2017): "Identifying and Countering Fake News". En Arizona Legal Studies, Discussion Paper No 17-15, pp. 1-33.

VIZOSO, Ángel y VÁZQUEZ-HERRERO, Jorge (2019): "Plataformas de fact-checking en español. Características, organización y método". En Communication $\mathcal{E}$ Society, año $32 \mathrm{~N}^{\circ} 1$, pp. 127-14.4.

WOLLEY, Samuel C. y HOWARD, Philip N. (2017): Computational Propaganda Worldwide: Executive Summary. Working paper 2017-11 (Oxford: Computational Propaganda Research Project). 